\title{
Componente quístico del cáncer renal: Revisión conceptual
}

\author{
Sánchez-Martín FM, Pascual Queralt M, Martínez-Rodríguez RH, Algaba Arrea F*, \\ Millán Rodríguez F, Palou Redorta J, Villavicencio Mavrich H.
}

Servicios de Urología y *Anatomía Patológica. Fundación Puigvert. Barcelona.

Actas Urol Esp. 2008;32(5):507-516

\section{RESUMEN}

COMPONENTE QUÍSTICO DEL CÁNCER RENAL: REVISIÓN CONCEPTUAL

El componente quístico del cáncer renal (CR) aparece en el estudio radiológico y queda consolidado con el examen anatomopatológico. El concepto "cáncer renal quístico" o "tumor renal quístico" es de uso habitual y comprende una serie de entidades que van desde los CR con patrón de crecimiento quístico a aquellos que poseen cavidades pseudoquísticas o se hallan imbricados en cualquiera de las enfermedades renales que presentan quistes renales. Diversas publicaciones utilizan de forma indistinta el calificativo "quístico" sin esperar al estudio anatomopatológico, provocando confusión en la terminología. La gran variabilidad en la forma de presentación tanto del CR como de las enfermedades quísticas renales produce distintas formas de presentación radiológica en que se mezclan áreas sólidas y otras de contenido líquido, aunque sólo el examen patológico podrá afirmar que se trata de un CR quístico genuino. Sólo el $\mathrm{CR}$ con patrón de crecimiento quístico y el carcinoma multilocular quístico pueden ser llamados con propiedad tumores renales quísticos. Para el resto de entidades, en especial durante el estudio iconográfico, es más adecuado utilizar expresiones no concluyentes como "masa renal de configuración quística" o "tumor renal de aspecto quístico".

Palabras clave: Tumor renal quístico. Cáncer renal. Quiste renal. Patrón quístico. Pseudoquiste renal.

\section{ABSTRACT}

\section{THE CYSTIC COMPONENT IN THE RENAL CANCER: CONCEPTUAL OVERIEW}

The renal cancer (RC) cystic component is on the radiological tests and could be consolidate with pathological analysis. The concepts "cystic renal cancer" or "cystic renal tumor" contain a group of entities range from cystic grown pattern RCs to pseudocystic tumors as well as cystic renal diseases coinciding with the RC. The CR and the cystic renal diseases have a great variety to sorts of presentations, giving different ways of radiological images, blending solid and cystic areas. Some papers use indiscriminately expression "cystic" without pathologic proof. Just cystic grown pattern RCs and multilocular cystic carcinoma could be named "cystic renal tumors". For de rest, especially over image study, is more suitable to use expressions as "renal tumor of cystic configuration", while pathologic report are available.

Keywords: Cystic renal tumor. Renal cancer. Renal cyst. Cystic pattern. Renal pseudocyst.

$\mathrm{E}$ 1 componente quístico del cáncer renal (CR) se manifiesta durante el estudio radiológico (que traduce la imagen macroscópica) y con el examen anatomopatológico (que aporta, además de la visión macro, la imagen microscópica y definitiva sobre la naturaleza del tumor). Las denominaciones "cáncer renal quístico" o "tumor renal quístico" comprenden, desde el punto de vista clínico y radiológico, cualquier tumoración renal sugestiva de proceso neoformativo en la que hay presencia de cavidades llenas de líquido a la visión macroscópica, tanto constitutivas del propio tumor como asociadas a enfermedades quísticas renales preexistentes ${ }^{1,2}$. El estudio anatomopatológico permite emplear la terminología "quístico" de forma más objetiva, para los tumores que contienen un componente intrínseco de lesiones cavitarias, rellenas de líquido, esféricas y epitelizadas de epitelio maligno. Cuando el número o tamaño de las lesiones predomina sobre el componente sólido del CR se aplica de forma genuina el 
término "patrón quístico". Asimismo, el carcinoma quístico multilocular es una entidad diferencial descrita en los últimos años, que merece con propiedad el apelativo "quístico"3. La coexistencia del cáncer renal con enfermedades quísticas renales ${ }^{4}$ o la presencia de pseudoquistes ${ }^{5,6}$ no constituyen una lesión tumoral quística en sentido estricto por lo que debe evitarse su clasificación en esta categoría.

En 5.721 pacientes con CR, el 3,9\% tuvo relación con algún tipo de enfermedad renal quística, entre las que destacan quistes simples (37\%), enfermedad quística adquirida del adulto (28\%), quistes renales multiloculares (10\%) y poliquistosis renal hereditaria $(1 \%)^{7}$. Las diferentes formas de entender el concepto "cáncer renal quístico" o "tumor renal quístico” de urólogos, radiólogos y patólogos responde a la gran cantidad y variabilidad de las diversas entidades renales quísticas relacionadas con el $\mathrm{CR}^{8}$. También la gran variabilidad celular y arquitectural del propio CR contribuye a ello. Las posibilidades oscilan entre un quiste simple complicado a un verdadero $\mathrm{CR}$ de patrón de crecimiento quístico, así como toda la serie de situaciones patológicas que se tienen expresión quística en el riñón (Tabla 1). Existen trabajos que utilizan los términos de forma equívoca como "cáncer (o carcinoma) renal quístico" o "tumor renal quístico" en cualquiera de estas circunstancias, lo que contribuye a la confusión conceptual $^{5,9-13}$.

\section{OBJETIVIDAD DEL CONCEPTO “TUMOR RENAL QUÍSTICO"}

El componente quístico del CR se encuadra dentro de 2 conceptos que pueden colisionar y producir confusión si no se utiliza un lenguaje claro y homogéneo. Se trata, en primer lugar de diferenciar bien ambas situaciones:
- Concepto anatomopatológico: Sólo se consideran quísticos los tumores que contienen quistes como componente estructural propio de la neoplasia. El quiste (o quistes) neoplásico maligno viene definido como la lesión cavitaria, esférica, llena de líquido, cuyo epitelio de revestimiento es neoplási$\mathrm{co}^{14}$. Desde el punto de vista anatomopatológico sólo los CR con patrón de crecimiento quístico y los carcinomas multiloculares quísticos pueden ser calificados como verdaderos tumores renales quísti$\cos ^{16}$. No pueden considerarse quísticos desde el punto de vista anatomopatológico los tumores que aparecen junto a una lesión quística que, una vez examinada al microscopio, no reúne los criterios citados anteriormente (por ser de epitelio benigno o no estar epitelizada).

- Concepto radiológico: Puede considerar quísticas todas las masas renales que tienen aspecto cavitario o se hallan contiguas a una lesión quísti$\mathrm{ca}^{15}$ aunque ésta, finalmente, no forme parte de la neoplasia o no reúna criterios de anatomopatológicos de malignidad ${ }^{10}$. Se tiene en consideración el aspecto macroscópico ecográfico o densitométrico de la tumoración (contenido líquido) con independencia del dictamen anatomopatológico posterior. Si bien es posible la coincidencia ocasional de CR de aspecto radiológico quístico y el dictamen patológico final de patrón quístico (Fig. 1) la terminología "tumor quístico" sólo debería aplicarse una vez disponible la descripción anatomopatológica. De forma paradójica existen $\mathrm{CR}$ de patrón quístico genuino cuyos microquistes sólo son evidenciables al microscopio, presentando un aspecto macroscópico o radiológico de tumoración sólida.

La ambivalencia terminológica permite afirmaciones como “...la categoría Bosniak IIF de quiste

Tabla 1. El concepto "quístico" es utilizado indistintamente en cualquiera de las entidades señaladas, si bien sólo es objetivamente aceptable hacerlo en las dos primeras (en negrilla ४), en base al criterio anatomopatológico.

\begin{tabular}{|c|c|}
\hline ENTIDAD & RAZÓN \\
\hline 1. Carcinoma multilocular quístico & Entidad anatomopatológica propia del CR. \\
\hline 2. CR quístico & Variedad de patrón de crecimiento del CR. \\
\hline 3. Nefroma quístico & Entidad anatomopatológica propia, benigna. \\
\hline 4. Quiste renal complejo & Clasificados en las categorías de Bosniak. \\
\hline 5. CR pseudoquístico & Presencia de cavidades por necrosis o hemorragia. \\
\hline 5. $\mathrm{CR}+$ quiste simple & Coincidencia de CR y quiste simple ranal \\
\hline 7. $\mathrm{CR}+$ enfermedades quísticas renales & Coincidencia de CR y enfermedad quística renal \\
\hline
\end{tabular}



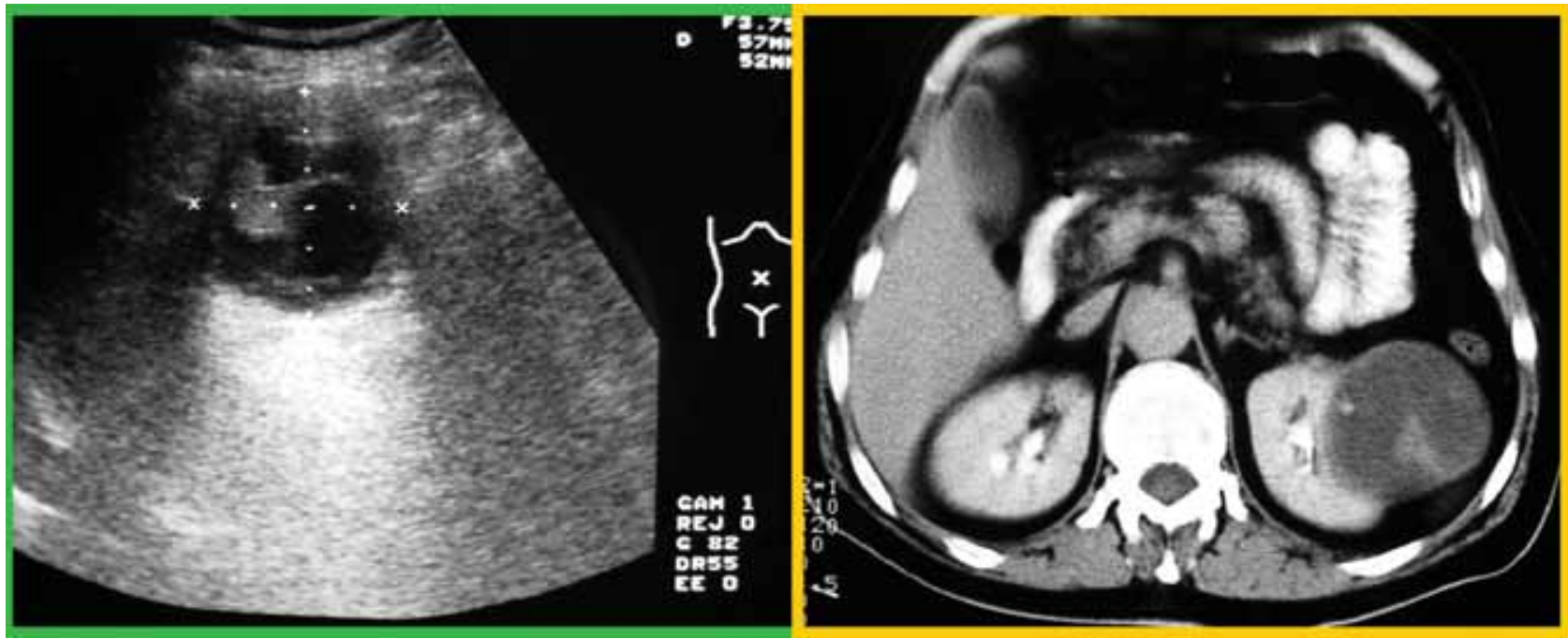

FIGURA 1. Ecografía y TC abdominal que muestran lesión quistica compleja renal izquierda tipo Bosniak IV, catalogada radiológicamente como "tumor de aspecto quistico" que se confirma al examen de la pieza de nefrectomía radical izquierda: Adenocarcinoma renal, de células claras, patrón quistico, grado II, estadio T1. Este CR cumple tanto con el criterio radiológico como con el anatomopatológico.

renal es útil como indicador precoz del carcinoma quístico" ${ }^{1}$, poco clarificadoras. En el proceso diagnóstico y mientras no se dispone de un resultado patológico definitivo pueden emplearse términos como "tumor renal de configuración quística", tal como han señalado acertadamente algunos gru$\operatorname{pos}^{17,18}$ o bien de tumoración o masa renal quística como se viene haciendo después del establecimiento de las categorías de Bosniak ${ }^{19}$. La TC si bien tiene una sensibilidad del 100\% para detectar tumoraciones quísticas, presenta una baja especificidad para determinar si son o no malignas ${ }^{20}$.

\section{AMPLITUD DEL CONCEPTO “TUMOR RENAL QUISTICO"}

Las diferentes lesiones quísticas renales, relacionadas o no con el CR ofrecen una gran variabilidad de posibilidades conceptuales, si bien es recomendable recurrir al uso de una nomenclatura objetiva y uniforme. Es posible establecer una gradación en cuanto a la conveniencia de uso del término "quístico” en el CR, donde sólo el CR de patrón de crecimiento quístico y el CR quístico multilocular pueden ser llamados objetivamente tumores renales quísticos (Fig. 2). Los tumores en los que puede emplearse con propiedad la denominación "quístico" son:

\section{CR con patrón de crecimiento quistico}

El CR puede presentar cuatro patrones clásicos de crecimiento celular: tubular, papilar, sólido y quístico $(12 \%)^{21}$. Se trata de una forma evolutiva de patrón tubular ${ }^{23}$, cuando los túbulos se dilatan de forma suficiente y las formaciones quísticas predominan siendo casi siempre visibles a la inspección macroscópica. Se trata de lesiones esféricas propias del CR, rellenas de líquido y revestidas de epitelio de características malignas ${ }^{23}$, diferentes a los CR en los que la necrosis y la hemorragia han provocado cavidades no epitelizadas (pseudoquistes) ${ }^{22}$ o de aquéllas que se desarrollan junto a un quiste renal de

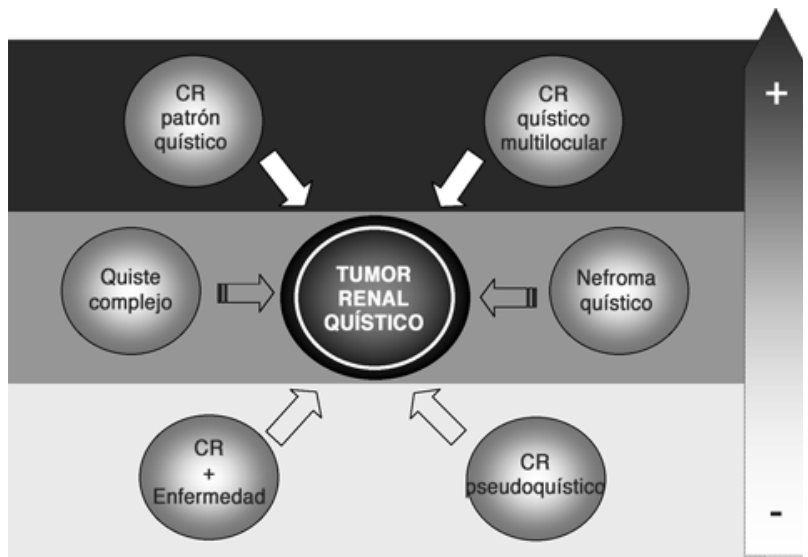

FIGURA 2. Gradación (de más a menos) para el empleo del concepto "quistico" en las lesiones renales. Sobre fondo más oscuro los tumores que pueden ser llamados de forma genuína quisticos (con criterio anatomopatológico). En gris medio los tumores que pueden ser definidos radiológicamente como "de aspecto quístico, con independencia de que la patologia confirme su pertenencia a este patrón. En gris tenue los tumores renales que no deberian ser llamados "quisticos". 
cualquier etiología, cercano al tumor pero que no participa en el proceso neoplásico. El componente quístico y sólido (estromal) de una $\mathrm{CR}$ se halla entremezclado por lo que es el mayor porcentaje de formaciones quísticas el factor que determina su adscripción histológica al patrón quístico ${ }^{23}$. El pronóstico es mejor cuanto más lesión quística posee la neoplasia, ya que equivale a una menor cantidad de masa tumoral ${ }^{24}$. En ocasiones la zona quística es única y de gran tamaño denominándose entonces carcinoma quístico unilocular ${ }^{25,26}$ o cistadenocarcinoma renal, variedad del CR papilar ${ }^{27}$, aunque estas nomenclaturas están ya obsoletas. Cuando se trata de quistes múltiples simples puede aplicarse de forma inapropiada la denominación multilocular, pudiendo ser confundido con una variante del CR de células claras ${ }^{28}$. Algunos autores emplean denominaciones diferentes como "carcinoma de células renales multiquístico” complicando aún más la distinción de unos y otros conceptos ${ }^{29}$. Cuando los quistes son de tamaño suficiente la TC muestra una lesión mixta en la que se aprecian zonas de contenido líquido que pueden ser de gran tamaño, relacionadas con otras áreas más sólidas. La pared de los quistes suele mostrar áreas irregulares, engrosadas y que captan contraste iodado, siendo éste un aspecto muy específico de malignidad ${ }^{30}$. Los tumores quísticos renales pueden mostrar también un patrón avascular ${ }^{31}$ si bien las paredes y septos tumorales pueden estar dotados de neovascularización ${ }^{32}$.

Existen tumoraciones que no son consideradas quísticas desde el punto de vista patológico como el CR de ductos colectores de bajo grado, también llamado, carcinoma tubuloquístico de bajo grado (unos 100 casos comunicados), presenta en ocasiones un aspecto micro-multiquístico ${ }^{33}$ (nomenclatura aún no aceptada por la OMS), que no debe ser confundido con el carcinoma multilocular quístico que se describe más adelante. El nefroblastoma (tumor del Wilms) puede adquirir configuración quística ${ }^{17}$, y procesos proliferativos renales como el linfangioma ${ }^{34}$ terato$\mathrm{ma}^{35}$, hamartoma ${ }^{12}$, angiomiolipoma ${ }^{36}$, oncocitoma ${ }^{37}$ y linfoma ${ }^{38}$ pueden mostrar un aspecto macroscópico quístico, siendo el examen de la pieza la única forma de asegurar el diagnóstico.

\section{Carcinoma multilocular quistico}

Se trata de una variante de CR de células claras $^{3}$, según la clasificación de 2004 de la $\mathrm{OMS}^{39}$. El origen de esta neoplasia renal se halla en el túbulo proximal, al igual que el resto de CR. El componente sólido sólo ocupa el 10\% del volumen tumoral total ${ }^{40}$. Existen muy pocos casos publicados en la literatura mundial (unos 45), a los que se atribuye buen pronóstico ${ }^{41}$. La terminología "quístico" es adecuada aquí, una vez obtenido el estudio histopatológico, si bien es posible observar trabajos en que se utiliza de forma inapropiada cuando la terminología no estaba definida hace unos $\operatorname{años}^{42}$. A la TC se aprecia un conglomerado quístico complejo, con pared y septos finos y regulares, sin una imagen nodular clara. El pronóstico es bueno ya que no se han descrito metástasis. El carcinoma multilocular quístico debe ser diferenciado asimismo del nefroma quístico o quiste multilocular renal, que es una entidad benigna y no tiene relación alguna con aquél. La terminología "multilocular" se utiliza de forma confusa en referencia a tumores renales que presentan cavidades multiseptadas ${ }^{40}$.

\section{Nefroma quistico o quiste multilocular renal}

Se trata de una entidad que cumple los siguientes criterios: tumoración de aspecto totalmente quístico bien delimitada respecto del parénquima renal, dividida por septos fibrosos y regulares ${ }^{43}$ compuestos de tejido bien diferenciado sin elementos de blastema ${ }^{44}$, aunque puedan hallarse ocasionales diferenciaciones heterólogas de tejidos maduros. En edad pediatrica el nefroma quístico se considera una variante benigna del nefroblastoma, pero en adultos es netamente una lesión benigna ${ }^{12}$. El nefroblastoma con diferenciación quística es una entidad diferente menos agresiva ${ }^{45}$. Existe controversia acerca del origen de esta enfermedad y se desconoce si es un tumor embrionario o una malformación congénita ${ }^{46}$. Una forma distinta de clasificar el nefroma quístico es hacerlo como tumor renal mixto epitelial y estromal, aunque existen discrepancias al respecto ${ }^{47}$. La TC muestra una lesión renal compleja con uno o varios quistes de tamaño grande, fina pared y contenido líquido, o bien un cúmulo de pequeños quistes, presencia de septos más gruesos y contenido pastoso, cuyo aspecto tomográfico es muy similar al $\mathrm{CR}$ quístico ${ }^{48}$. Sólo puede ser diagnosticado con seguridad una vez extirpado ${ }^{20}$. Se ha descrito la transformación maligna del nefroma quístico lo que contribuye a recomendar su abordaje quirúrgico ${ }^{49}$. 
Existen otras variedades tumorales que no deben ser calificadas como quísticas:

\section{CR pseudoquistico}

$\mathrm{El}$ rápido crecimiento tisular de cualquier $\mathrm{CR}$ produce fenómenos de necrosis y de hemorragia interna que se traducen en zonas líquidas intratumorales que, erróneamente, pueden ser calificados como "quísticas" en la descripción tomodensitométrica $^{50}$. Es más adecuado utilizar el término "pseudoquístico" cuando se presumen fenómenos de hemorragia o necrosis ${ }^{51}$. La pérdida de sustancia tumoral por necrosis refleja al elevado potencial proliferativo del CR, lo que traduce una mayor tasa de ganglios positivos, metástasis y peor supervivencia $^{52}$. El análisis histopatológico demuestra que la cavidad pseudoquística no se halla epitelizada ${ }^{53}$.

\section{CR coincidente con quiste renal simple}

Los quistes renales simples son lesiones esféricas de predominio medular, pared fina y regular, de contenido líquido transparente. La prevalencia de individuos con al menos un quiste renal simple varía con la edad: $0 \%$ entre los 15-29 años, 1,7\% entre los 30-49, 11,5\% entre los 50-70, y 22,1\% por encima de los 70 años. El CR puede presentarse sobre riñones con quistes renales simples (Fig. 3) en sus diversas formas de manifestación (hiliosinuquistosis y quistes corticales), sin que ello represente una asociación entre ambas entidades ${ }^{54}$. En un trabajo sobre "tumores quísticos renales" el 6\% correspondió a CR implantados en la pared de un

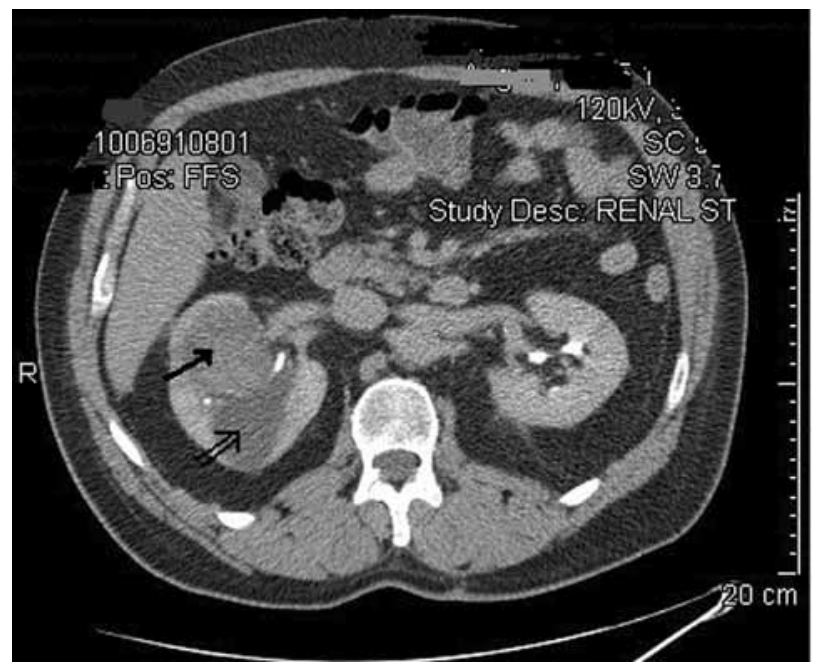

FIGURA 3: CR (flecha) junto a quiste simple (doble flecha), en la fase de eliminación nefrográfica de la TAC: Se aprecia la capacidad de la neoplasia para captar contraste. quiste simple, lo que señala una coincidencia de ambos procesos y el empleo confuso de la terminología ${ }^{9}$. Los quistes renales simples no son precursores de CR y su coincidencia es debida a la elevada prevalencia de aquéllos en la población adulta nor$\mathrm{mal}^{55}$. Generalmente existe una atrofia del epitelio del quiste simple en contacto con la lesión neoplásica que hace difícil sostener la teoría de su malignización. La eventual invasión de un quiste simple por parte de un CR es secundaria al carácter infiltrativo de la neoplasia que a una degeneración maligna del quiste.

Los quites simples suelen ser descubiertos casualmente y presentan un aspecto típico transónico, esférico y bien limitado a la ecografía. A la TC son de densidad líquida y uniforme, con cubierta fina $\mathrm{y}$ regular y sin capacidad de incorporar contraste iodado. Si presentan complicaciones (infección, hemorragia) muestran variaciones radiográficas (deformación, aumento de densidad o aparición de calcificaciones o zonas sólidas) que pueden plantear dudas diagnósticas con el $\mathrm{CR}$, tal como contempla la clasificación de Bosniak.

\section{Quiste renal complicado}

Bosniak estableció 4 categorías tomodensitométricas para clasificar los quistes renales, en un intento de prever el diagnóstico de CR y la consiguiente necesidad de tratamiento quirúrgico ${ }^{15,56}$. Sólo los que presentan componente sólido y los que captan contraste puede ser finalmente un carcinoma renal de patrón de crecimiento quístico ${ }^{11}$. En la Tabla 2 se detallan los criterios para encuadrar cada una de las categorías.

\section{CR coincidente con enfermedad quistica renal}

Cualquier CR puede desarrollarse sobre riñones afectos de enfermedades renales quísticas sin que ello signifique necesariamente relación directa entre el tumor y la enfermedad renal de base. Tampoco existe una predisposición del $\mathrm{CR}$ a adoptar un patrón de crecimiento quístico. El problema diagnóstico puede plantearse si la lesión sólida está en contacto con alguno de los quistes, por la dificultad de diferenciar un quiste complicado de una neoformación. Una vez extirpada la lesión puede determinarse la tipología anatomopatológica exacta del CR, al que no debe denominarse CR quístico por el simple hecho de coincidir con la enfermedad quística renal. La presencia de un patrón de crecimiento 
Tabla 2. Clasificación de Bosniak para quistes renales complicados y porcentaje de CR

\begin{tabular}{|c|c|c|c|}
\hline BOSNIAK I & $\begin{array}{l}\text { Simple } \\
\text { no complicado }\end{array}$ & $\begin{array}{l}\text { Pared fina, lisa y regular, contenido líquido homogéneo, } \\
\text { bien diferenciado del parénquima renal, sin captación de } \\
\text { contraste y sin calcificaciones. }\end{array}$ & 0 \\
\hline BOSNIAK II & $\begin{array}{l}\text { Mínimamente } \\
\text { complicado }\end{array}$ & $\begin{array}{l}\text { Pared regular y lisa, tabicación fina y lineal, calcificación lineal, } \\
\text { contenido hiperdenso, homogéneo, sin captación de contraste. }\end{array}$ & $<5$ \\
\hline BOSNIAK IIF & $\begin{array}{l}\text { Moderadamente } \\
\text { complicado }\end{array}$ & $\begin{array}{l}\text { Tabiques numerosos, engrosados, con mínima captación de } \\
\text { contraste, con calcificaciones lineales. }\end{array}$ & 5 \\
\hline BOSNIAK III & $\begin{array}{l}\text { Bastante } \\
\text { complicado }\end{array}$ & $\begin{array}{l}\text { Pared engrosada, tabiques numerosos, que pueden captar contraste, } \\
\text { calcificaciones irregulares. }\end{array}$ & $50-60$ \\
\hline BOSNIAK IV & Muy complicado & $\begin{array}{l}\text { Pared con fuerte irregularidad y nodulaciones, áreas internas } \\
\text { heterogéneas, elementos sólidos, captación zonal de contraste. }\end{array}$ & $70-100$ \\
\hline
\end{tabular}

celular quístico en el CR, aunque ello nada tiene que ver con la enfermedad de base ${ }^{57}$. En estos casos puede hablarse genuinamente de CR quístico y añadir en el informe los datos patológicos derivados de la enfermedad quística renal.

\section{CR asociado a enfermedad quistica adquirida del adulto.}

La incidencia de enfermedad quística renal adquirida en pacientes con insuficiencia renal terminal en tratamiento crónico con hemodiálisis oscila entre el $30-95 \% 58$, aumentando a medida que pasan años en diálisis ${ }^{59}$. La atrofia túbulointersticial y la dilatación de túbulos y glomérulos facilitan la aparición de múltiples quistes corticales y medulares. Los quistes miden 3-5 mm de media. El riesgo de desarrollo de una neoplasia renal en pacientes hemodializados durante largo tiempo es similar a los de la población general ${ }^{60}$, aunque hay autores que refieren un riesgo 3-6 veces superior ${ }^{61}$. Se ha comunicado una incidencia de $\mathrm{CR}$ en estos pacientes del $54,4 \%$, muy por encima del $6 \%$ de los que padecen insuficiencia renal y no son dializados ${ }^{62}$. El hallazgo del tumor suele ocurrir cuando las lesiones son menores de $2 \mathrm{~cm}$, pudiendo ser bilaterales en el $11 \%$ de casos $^{63}$. Algunos grupos siguen a sus pacientes en diálisis con ecografía o TC anual ${ }^{63,64}$.

\section{Poliquistosis hereditaria}

No se ha demostrado que esta enfermedad, que conduce a los pacientes a la insuficiencia renal terminal entre los 30-40 años aumente el riesgo de desarrollo de CR. Cuando el CR aparece se atribuye a una coincidencia de ambas entidades. Tampoco en este caso puede hablarse de CR quístico a partir de la imagen macroscópica, que muestra una lesión renal sólida entre multitud de lesiones quísticas de complejidad variable. Los riñones poliquísticos plantean dudas diagnósticas cuando presentan cambios en el contendido de alguno de los quistes, generalmente derivados de sobreinfección o hemorragia interna.

\section{CR en las neurofibromatosis}

La enfermedad de von Hippel-Lindau es autosómica dominante con mutaciones del gene supresor localizado en el cromosoma 3p25-26 $6^{65}$. Presenta quistes renales en el 60\% de los casos, adenomas en el 15\%, y CR de células claras en el 50\%, en ocasiones bilateral; con mayor frecuencia en la tercera y cuarta década de la vida ${ }^{66}$. Está descrito el nefroma quístico en esta enfermedad y su malignización ${ }^{9}$. El seguimiento de estos enfermos, frecuentemente con historia de CR familiar, permite el diagnóstico de tumores renales sólidos coexistiendo con los quistes. Además de la afectación renal existe hemangioma de retina, hemangioblastoma del cerebelo y en médula espinal, feocromocitoma, tumores endocrinos de páncreas y cistadenoma del epidídimo.

En la enfermedad de Pringle-Bourneville, o esclerosis tuberosa, es frecuente la presencia de quistes renales múltiples, fibromas $\mathrm{y}$ angiomiolipomas (algunos con escaso componente graso) ${ }^{67}$. Esta mezcla de lesiones quísticas y sólidas plantea problemas de diagnóstico diferencial radiológico con un tumor maligno ${ }^{68}$ aunque el desarrollo de CR de células claras es infrecuente ${ }^{69}$. La afectación tisular del sindrome es muy amplia e incluye distintos tejidos y lesiones: angiofibromas faciales, fibromas subungueales, fibromas y máculas cutáneas en ninguna de las dos entidades es adecuado usar el término "tumor renal quístico". 


\section{CR coincidente con lesiones quisticas renales benignas de etiología diversa}

Las enfermedades renales que tienen expresión quística o forman fenómenos cavitarios pueden coincidir con un $\mathrm{CR}$. Al mismo tiempo, la apariencia atípica de cualquiera de estas enfermedades (Tabla 3) puede dificultar su distinción de un CR. El patrón radiológico, la situación clínica, la microbiología y la citología constituyen las claves para un correcto diagnóstico diferencial, siendo necesaria la exéresis quirúrgica en algunos casos. Algunos pueden adoptar formas quísticas con lagunas de tejido sólido, en ocasiones parénquima con mayor o menor grado de nefritis intersticial, lo que obliga a un correcto diagnóstico diferencial.

\section{CONCLUSIONES}

La gran diversidad de posibilidades que ofrecen las formaciones quísticas renales incluidas o combinadas con el CR, dificultan que el concepto de cáncer renal quístico sea suficientemente claro y uniforme. Sólo el CR de patrón de crecimiento quístico y el carcinoma multilocular quístico (un tipo celular diferenciado del CR de células claras), pueden ser llamados con propiedad CR quísticos según un criterio anatomopatológico reproductible. No debieran llamarse quísticos aquellos tumores que coinciden, colisionan o se originan en una enfermedad quística renal preexistente o adyacente. Tampoco la necrosis o la hemorragia interna, que sólo son lesiones pseudoquísticas. El concepto anatomopatológi-

Tabla 3. Lesiones benignas de etiología diversa que pueden plantear el diagnóstico diferencial con el CR, cuando se apartan de su patrón morfológico típico.

\begin{tabular}{|c|c|}
\hline LESIÓN QUÍSTICA BENIGNA & CLAVES DIAGNÓSTICAS \\
\hline Quiste simple complicado & Contenido homogéneo \\
\hline Quiste complicado en poliquistosis & Estudio previo $=$ quiste simple \\
\hline & Control evolutivo $=$ mejoría $/$ estable \\
\hline & No captación contraste \\
\hline \multicolumn{2}{|l|}{ Riñón en esponja medular ${ }^{70}$} \\
\hline Hematoma renal & $\begin{array}{l}\text { Etiología causante previa inmediata } \\
\text { No lesión parenquimatosa hipercaptante } \\
\text { Control evolutivo = mejoría }\end{array}$ \\
\hline Absceso renal & $\begin{array}{l}\text { Contexto séptico } \\
\text { Control evolutivo = mejoría }\end{array}$ \\
\hline Angiomiolipoma atípico 36 & $\begin{array}{l}\text { Presencia de grasa } \\
\text { Control evolutivo = mejoría /estable }\end{array}$ \\
\hline Pielonefritis xantogranulomatosa ${ }^{71}$ & $\begin{array}{l}\text { Contexto litiasis / ITU } \\
\text { Células xànticas en orina } \\
\text { Ausencia nódulos hipercaptantes }\end{array}$ \\
\hline Tuberculosis renal & $\begin{array}{l}\text { Estenosis piélica } \\
\text { Ausencia nódulos hipercaptantes } \\
\text { Estudio bacteriológico positivo }\end{array}$ \\
\hline Quiste hidatídico $^{72}$ & $\begin{array}{l}\text { Contexto sociolaboral } \\
\text { Presencia vesículas hijas } \\
\text { No captación contraste en zona interna } \\
\text { Test sexológico positivo } \\
\text { Control evolutivo = mejoría /estable }\end{array}$ \\
\hline Fístula arterio-venosa & $\begin{array}{l}\text { Flujo arterio-venoso aumentado } \\
\text { Calcificaciones curvas laminares } \\
\text { Captación contraste masivo uniforme } \\
\text { Control evolutivo = mejoria /estable }\end{array}$ \\
\hline Divertículo calicilar o piélico ${ }^{73}$ & $\begin{array}{l}\text { Relleno de contraste en UIV / TAC } \\
\text { No captación contraste } \\
\text { Control evolutivo = estable }\end{array}$ \\
\hline $\begin{array}{l}\text { Hidronefrosis }{ }^{74} \\
\text { Pielón superior }\end{array}$ & $\begin{array}{l}\text { Morfología típica a UIV } \\
\text { No captación contraste } \\
\text { Control evolutivo = estable }\end{array}$ \\
\hline
\end{tabular}


co "quístico" se basa en la presencia mayoritaria de estructuras quísticas (con epitelio maligno) en el tumor, mientras que el concepto radiológico incluye toda lesión renal sólida o mixta que presenta áreas líquidas en su seno, incurriendo en el empleo de una nomenclatura imprecisa. La clasificación de Bosniak referente a los quistes complejos permite encuadrar de forma correcta aquellos que muestran aspecto tumoral durante el proceso de diagnóstico, pero no significa que los tumores que muestran aspecto radiológico quístico correspondan finalmente a un CR quístico genuino. Para la generalidad de masas renales de aspecto radiológico quístico, pendientes de diagnóstico histopatológico, puede utilizarse el término "masa renal de configuración quística".

\section{REFERENCIAS}

1. Hartman DS, Davis CJ Jr, Johns T, Goldman SM. Cystic renal cell carcinoma. Urology. 1986 Aug;28(2):145-153.

2. Prando A, Prando D, Prando P. Renal cell carcinoma: unusual imaging manifestations. Radiographics. 2006 Jan-Feb;26(1): 233-244.

3. Koga S, Nishikido M, Hayashi T, Matsuya F, Saito Y, Kanetake $\mathrm{H}$. Outcome of surgery in cystic renal cell carcinoma.Urology. 2000 Jul;56(1):67-70.

4. Weibl P, Lutter I, Breza J, Pechan J, Blazko M, Gajdosova T, Pindak D. Cystic renal cell carcinoma-rare clinical finding. Radiographic variations of tumor/cyst appearance and further diagnostic work-up. Bratisl Lek Listy. 2006;107(3):96-100.

5. Aubert S, Zini L, Delomez J, Biserte J, Lemaitre L, Leroy X. Cystic renal cell carcinomas in adults. Is preoperative recognition of multilocular cystic renal cell carcinoma possible? Urol. 2005 Dec; 174(6):2115-2119.

6. Castineiras J, Parra R, Lopez A, Yaro C, Alvarez-Ossorio JL, Gonzalez D, Rodriguez-Rubio F. Neoplasia renal desarrollada en una cavidad pseudoquística. Actas Urol Esp. 1994 Mar;18 (3): 241-244.

7. Hatano T, Koyama Y, Hayakawa M, Ogawa Y, Osawa A. Evidence for association between renal cell carcinomas and renal cystic diseases: nationwide survey in Japan. Nippon Hinyokika Gakkai Zasshi. 1996 Dec;87(12):1297-1304.

8. Hora M, Hes O, Michal M, Boudova L, Chudacek Z, Kreuzberg B, Klecka J. Extensively cystic renal neoplasms in adults (Bosniak classification II or III)-possible "common" histological diagnoses: multilocular cystic renal cell carcinoma, cystic nephroma, and mixed epithelial and stromal tumor of the kidney. Int Urol Nephrol. 2005;37(4):743-750.

9. Levy P, Helenon O, Merran S, Paraf F, Mejean A, Cornud F, Moreau JF. Cystic tumors of the kidney in adults: radio-histopathologic correlations. J Radiol. 1999 Feb;80(2):121-133.

10. Dalla-Palma L, Pozzi-Mucelli F, di Donna A, Pozzi-Mucelli RS. Cystic renal tumors: US and CT findings. Urol Radiol. 1990;12 (2):67-73.

11. Yamashita Y, Watanabe O, Miyazaki T, Yamamoto H, Harada M, Takahashi M. Cystic renal cell carcinoma. Imaging findings with pathologic correlation. Acta Radiol. 1994 Jan;35(1):19-24.

12. Eble JN, Bonsib SM. Extensively cystic renal neoplasms: cystic nephroma, cystic partially differentiated nephroblastoma, multilocular cystic renal cell carcinoma, and cystic hamartoma of renal pelvis. Semin Diagn Pathol. 1998 Feb;15(1):2-20.
13. Garrido Rivas C, Sanroma Ortueta I, Garmendia Larrea JC, Ruiz Diaz I, Lopez Garcia JA, Arocena Lanz F. Adenocarcinoma renal quístico. Arch Esp Urol. 1990 Nov-Dec;43(9):1015-1018.

14. Algaba F, Moreno A, Trias I: Tumores renales. En Uropatologia tumoral. Algaba F, Moreno A, Trias I Eds. Ed. Pulso. Barcelona. 1996.

15. Israel GM, Bosniak MA. An update of the Bosniak renal cyst classification system. Urology. 2005 Sep;66(3):484-488.

16. Algaba F, Arce Y, Trias I, Santaularia JM, Rosales A. Aplicación clínica de las actuales clasificaciones del cáncer renal. Actas Urol Esp. 2006 Apr;30(4):372-385.

17. Pascual Samaniego M, Calleja Escudero J, Alvarez Gago T, Gonzalo Rodriguez V, Muller Arteaga C, Fernandez del Busto E. Tumor de Wilms en el adulto. Actas Urol Esp. 2004 Jul-Aug;28 (7):544-548.

18. Alapont JM, Andreu Garcia A, Herrero Polo E, Schiefenbusch Munne E, Botella Almodovar R, Brotons Marquez JL, Llamazares Cacha G. Quiste renal complejo. A propósito de un caso. Actas Urol Esp. 2004 sep;28(8):610-613.

19. Spaliviero M, Herts BR, Magi-Galluzzi C, Xu M, Desai MM, Kaouk JH, Tucker K, Steinberg AP, Gill IS. Laparoscopic partial nephrectomy for cystic masses. J Urol. 2005 Aug; 174(2): 614-619.

20. del Riego Martin M, Landeras Alvaro R, Lopez Rasines G, Calabia de Diego A, Pagola Serrano MA, Gutierrez Banos JL, Hernandez Rodriguez R. Computerized axial tomography (CAT) and echography (US) of multilocular cystic nephroma. Arch Esp Urol. 1996 Jul-Aug;49(6):619-621.

21. Bielsa O, Lloreta J, Gelabert-Mas A. Cystic renal cell carcinoma: pathological features, survival and implications for treatment. Br J Urol. 1998 Jul;82(1):16-20.

22. Bielsa Gali O, Arango Toro O, Cortadellas Angel R, Castro Santamaría R, Griñó Garreta J, Gelabert-Mas A. El diagnóstico preoperatorio de las masas renales quísticas complejas. Arch Esp Urol. 1999 Jan-Feb;52(1):19-25.

23. Algaba F, Moreno A, Trias I: Tumores renales. En Uropatologia tumoral. Algaba F, Moreno A, Trias I Ed. Ed. Pulso. Barcelona. 1996.

24. Onishi T, Oishi Y, Goto H, Tomita M, Abe K, Sugaya S. Cystassociated renal cell carcinoma: clinicopathologic characteristics and evaluation of prognosis in 27 cases. Int J Urol. 2001 Jun;8(6):268-274.

25. Desligneres S.J. Clear cell unilocular and multilocular cystic renal tumors and in situ clear cell intratubular carcinoma. J Urol (Paris). 1993;99(3):111-117.

26. Han KR, Janzen NK, McWhorter VC, Kim HL, Pantuck AJ, Zisman A, Figlin RA, Dorey FJ, Said JW, Belldegrun AS. Cystic renal cell carcinoma: biology and clinical behavior. Urol Oncol. 2004 Sep-Oct;22(5):410-414.

27. Terachi T. Diagnosis and treatment of renal cell carcinoma accompanying the cystic lesion. Hinyokika Kiyo. 1995 Sep;41(9):697-701.

28. Desligneres S. Cystic clear cell tumors of the kidney. Arch Anat Cytol Pathol. 1992;40(5-6):255-260.

29. Rodriguez IM, de Alava E; Lozano MD y cols. Carcinoma de células renales multiquístico. ¿Existe una verdadera evidencia de que estos tumores son neoplasias malignas? Estudio clínicopatológico de seis casos”. Rev Esp Patol. 2002:35:201.

30. Benjaminov O, Atri M, O'Malley M, Lobo K, Tomlinson G. Enhancing component on $\mathrm{CT}$ to predict malignancy in cystic renal masses and interobserver agreement of different CT features. AJR Am J Roentgenol. 2006 Mar;186(3):665-672.

31. Onishi T, Oishi Y, Goto H, Yanada S, Abe K. Histological features of hypovascular or avascular renal cell carcinoma: the experience at four university hospitals.Int J Clin Oncol. 2002 Jun;7(3): 159-164. 
32. Fujikawa S, Nishikawa K, Yonemura S, Arima K, Yanagawa M, Sugimura Y, Kobayashi S, Takeda H, Kawamura J.A case of cystic renal cell carcinoma: clinical usefulness of CT arteriography.Hinyokika Kiyo. 2003 Aug;49(8):475-477.

33. Farah R, Ben-Izhak O, Munichor M, Cohen H.: Low-grade renal collecting duct carcinoma. A case report with histochemical, immunohistochemical, and ultrastructural study. Ann Diagn Pathol 2005;9:46-48.

34. Caduff RF, Schwobel MG, Willi UV, Briner J.Lymphangioma of the right kidney in an infant boy. Pediatr Pathol Lab Med. 1997;17(4):631-637.

35. Mallen Mateo E, Sancho Serrano C, Gil Sanz MJ, Borque Fernando A, Yague Romeo D, Rioja Sanz LA. Teratoma renal, aportación de un caso y revisión de la literatura. Actas Urol Esp. 2005 May;29(5):516-518

36. Fine SW, Reuter VE, Epstein JI, Argani P. Angiomyolipoma with epithelial cysts (AMLEC): a distinct cystic variant of angiomyolipoma. Am J Surg Pathol. 2006 May;30(5):593-599.

37. Leroy X, Aubert S, Lemaitre L, Haffner J, Biserte J, Gosselin B.Multilocular cystic renal oncocytoma. J Clin Pathol. 2006 Feb;59(2):223-224.

38. Sheth S, Ali S, Fishman E.Imaging of renal lymphoma: patterns of disease with pathologic correlation. Radiographics. 2006;26(4):1151-1168.

39. Comperat E, Camparo P, Vieillefond A. WHO classification 2004: tumors of the kidneys. J Radiol. 2006 Sep;87(9):1015-1024.

40. Nassir A, Jollimore J, Gupta R, Bell D, Norman R.Multilocular cystic renal cell carcinoma: a series of 12 cases and review of the literature. Urology. 2002 Sep;60(3):421-427.

41. Suzigan S, Lopez-Beltran A, Montironi R, Drut R, Romero A, Hayashi T, Gentili AL, Fonseca PS, deTorres I, Billis A, Japp LC, Bollito E, Algaba F, Requena-Tapias MJ. Multilocular cystic renal cell carcinoma : a report of 45 cases of a kidney tumor of low malignant potential. Am J Clin Pathol. 2006 Feb;125 (2):217-222.

42. Romero Ortiz A, López-Beltrán A, Pérez Luque A, Requena Tapia MJ. Carcinoma renal quístico multilocular. Estudio clinico-patológico de 14 casos. Arch Esp Urol 2005 Jan-Feb;58 (1):9-16.

43. del Riego M, Landeras R, Lopez-Rasines G, Calabia A, Pagola MA, Gutierrez-Banos JL, Hernandez-Rodriguez R. Estudio mediante Tomografía Axial Computerizada (TAC) y ecografía (US) del nefroma quístico multilocular. Arch Esp Urol. 1996 Jul-Aug;49(6):619-621.

44. Agrons GA, Wagner BJ, Davidson AJ, Suarez ES. Multilocular cystic renal tumor in children: radiologic-pathologic correlation.Radiographics. 1995 May;15(3):653-669.

45. Valero Puerta JA, Sanchez Gonzalez M, Medina Perez M, Valpuesta Fernandez I. Nefrectomía parcial en el nefroblastoma quístico partialmente diferenciado. Arch Esp Urol. 1998 Dec;51 (10): 1032-1034

46. Gonzalez-Escalante A, Garcia-Riestra V, Fernandez-Garcia ML, Relea A, Beiras M, Varela M, Sarandeses A, Alcazar JJ. Quiste multilocular. Diagnóstico preoperatorio con TAC. Arch Esp Urol. 1993 Jul-Aug;46(6):518-521.

47. Jevremovic D, Lager DJ, Lewin M.Cystic nephroma (multilocular cyst) and mixed epithelial and stromal tumor of the kidney: a spectrum of the same entity? Ann Diagn Pathol. 2006 Apr; 10(2):77-82

48. Parienty RA, Pradel J, Imbert MC, Picard JD, Savart P. Computed tomography of multilocular cystic nephroma. Radiology. 1981 jul;140(1):135-139.

49. Sambuis C, Albouy B, Riopel C, Gobet F, Grise P, Pfister C. Multilocular cystic nephroma in an adult: diagnostic and therapeutic strategy.Prog Urol. 2005 Apr;15(2):315-318.
50. Torres Gomez FJ, Torres Olivera FJ, Garcia Escudero A. Adenoma renal metanéfrico de predominio quístico. A propósito de uma caso. Arch Esp Urol. 2006 Jan-Feb;59(1):90-93.

51. Hirasawa K, Isurugi K, Oyamatsu T, Miwa T, Honma Y. Coexistence of cyst and tumor in the same kidney: a case report. Hinyokika Kiyo. 1990 Nov;36(11):1313-1316. (Abstract)

52. C Lam JS, Shvarts O, Said JW, Pantuck AJ, Seligson DB, Aldridge ME, Bui MH, Liu X, Horvath S, Figlin RA, Belldegrun AS. Clinicopathologic and molecular correlations of necrosis in the primary tumor of patients with renal cell carcinoma. Cancer. 2005 Jun 15;103(12):2517-2525.

53. Brinker DA, Amin MB, de Peralta-Venturina M, Reuter V, Chan DY, Epstein JI. Extensively necrotic cystic renal cell carcinoma: a clinicopathologic study with comparison to other cystic and necrotic renal cancers.Am J Surg Pathol. 2000 Jul;24(7):988-995.

54. Ljungberg B, Holmberg G, Sjodin JG, Hietala SO, Stenling R. Renal cell carcinoma in a renal cyst: a case report and review of the literature. J Urol. 1990 Apr;143(4):797-799.

55. Hayakawa M, Hatano T, Tsuji A, Nakajima F, Ogawa Y.Patients with renal cysts associated with renal cell carcinoma and the clinical implications of cyst puncture: a study of 223 cases. Urology. 1996 May;47(5):643-646.

56. Bosniak MA.Cystic renal masses: a reevaluation of the usefullness of the Bosniak Classification System. Acad Radiol. 1996 Nov;3(11):981-984.

57. Tickoo SK, dePeralta-Venturina MN, Harik LR, Worcester HD, Salama ME, Young AN, Moch H, Amin MB. Spectrum of epithelial neoplasms in end-stage renal disease: an experience from 66 tumor-bearing kidneys with emphasis on histologic patterns distinct from those in sporadic adult renal neoplasia. Am J Surg Pathol. 2006 Feb;30(2):141-153.

58. Basile JJ, McCullough DL, Harrison LH, Dyer RB. End stage renal disease associated with acquired cystic disease and neoplasia.J Urol. 1988 Nov; 140(5):938-943.

59. Yokoyama O, Miyazaki K, Ishida T, Fujita Y, Miyazaki R, Muramoto H, Nakashima T, Watanabe K. Clinical evaluation of renal cell carcinoma and acquired cystic disease of the kidney in long-term dialysis patients. Hinyokika Kiyo. 1991 Feb;37(2): 107-112.(Abstract).

60. Anderson GA, Degroot D, Lawson RK. Polycystic renal disease. Urology. 1993 Oct;42(4):358-364.

61. Levine E. Renal cell carcinoma in uremic acquired renal cystic disease: incidence, detection, and management. Urol Radiol. 1992;13(4):203-210.

62. Peces R, Martinez-Ara J. Renal cell carcinoma co-existent with other renal disease: clinico-pathological features in pre-dialysis patients and those reeiving dialysis or renal transplantation. Nephrol Dial Transplant (2004) 19: 2789-2796.

63. Kojima Y, Takahara S, Miyake O, Nonomura N, Morimoto A, Mori H. Renal cell carcinoma in dialysis patients: a single center experience. Int J Urol. 2006 Aug; 13(8):1045-1048.

64. Farivar-Mohseni H, Perlmutter AE, Wilson S, Shingleton WB, Bigler SA, Fowler JE Jr. Renal cell carcinoma and end stage renal disease. J Urol. 2006 Jun;175(6):2018-2020; discussion 2021.

65. Granata A, Sessa A, Righetti M, Cordaro S, Leone G, Figura M, Fatuzzo P, Rapisarda F, Di Maria E, Ciotti P, Mandich P, Nardo A, Ferrone M, Gallone S, Liuzzo G. Juvenile renal cell carcino$\mathrm{ma}$ as first manifestation of von Hippel-Lindau disease. J Nephrol. 2004 Mar-Apr;17(2):306-310.

66. Grubb RL 3rd, Choyke PL, Pinto PA, Linehan WM, Walther MM. Management of von Hippel-Lindau-associated kidney cancer. Nat Clin Pract Urol. 2005 May;2(5):248-255.

67. Sampson JR, Patel A, Mee AD.: Multifocal renal cell carcinoma in sibs from a chromosome 9 linked (TSC1) tuberous sclerosis family. J Med Genet. 1995;32(11):848-850. 
68. Patel U, Simpson E, Kingswood JC, Saggar-Malik AK.Tuberose sclerosis complex: analysis of growth rates aids differentiation of renal cell carcinoma from atypical or minimal-fat-containing angiomyolipoma. Clin Radiol. 2005 Jun;60(6):665-673; discussion 663-664.

69. Gottfried HW, Miller K, de Petriconi R, Wenderoth UK, Hautmann RE. Kidney carcinoma in Bourneville-Pringle disease. Urologe A. 1992 Mar;31(2):91-93.

70. Fellegara G, Froio E, Luong TV, Campanini N, Facchini F, Cortellini P, Melissari M. A case of medullary sponge kidney (Cacchi-Ricci disease) mimicking a renal mass. Arch Ital Urol Androl. 2005 Dec;77(4):202-205. (Abstract).

71. Rometti A, Kermarec J, Boschi J. Renal xanthogranulomaosis simulating a tumor of the collum associated with Cacchi-Ricci disease and so-called solitary cysts of the kidney. J Urol Nephrol (Paris). 1972 Mar;78(3):285-287.

72. Hasni Bouraoui I, Jemni H, Arifa N, Chebil M, Ben Sorba N, Tlili K. Imaging of renal hydatid cyst based on a series of 41 cases. Hasni Bouraoui I, Jemni H, Arifa N, Chebil M, Ben Sorba N, Tlili K.Prog Urol. 2006 Apr;16(2):139-144.
73. Kavanagh JJ, Gordon L, Curry NS, Ravenel JG. Calyceal diverticulum mimicking a renal tumor on FDG PET imaging. Clin Nucl Med. 2006 May;31(5):301-302.

74. Pereira Arias JG, Ullate Jaime V, Gutierrez Diez JM, Ateca DiazObregon R, Ramirez Rodriguez MM, Pereda Martinez E, Berreteaga Gallastegui JR. Tumores Concurrentes en un paciente con hidronefrosis gigante. Arch Esp Urol. 2006 Jan-Feb; 59 (1):84-87.

Correspondencia autor: Dr. F.M. Sánchez Martín Servicio de Urología.

Fundació Puigvert

Cartagena, 340 - 350 - 08025

Barcelona. Tel.: 934169700

E-mail autor: fsanchez@fundacio-puigvert.es Información artículo: Original - Cáncer renal Trabajo recibido: septiembre 2007

Trabajo aceptado: febrero 2008 